\title{
The Justification of Legitimate Defense-based on Jurisprudential Analysis of Yu Huan Case
}

\author{
Chenzhong Yue \\ Audit Office, Sichuan University of Arts and Science, Dazhou Sichuan, 635000, China
}

Key words: Legitimate defense, Personality right, Urgency, Limit.

\begin{abstract}
In the judicial practice, there are always very serious problems in the determination of legitimate defense. The result of the judgment is often far from common sense. The fundamental reason lies in the fact that the judicial personnel stand behind all the risks of defense responsible for the defenders bear. According to the facts found in the judgment of the first instance of the case, it is sufficient to confirm that the defendant can take defensive measures against illegal detention of obscene and obscene women, taking into account the time of illegal detention, the disparity of the two sides, and the possibility of illegal detention The degree of escalation, the use of weapons to take the first warning after the injury does not have the legal choice of other options, although the consequences of casualties, but also in line with the legitimate defense of the conditions, therefore, in the plea for Yu Huan was innocent the proper handling of the case will highlight the responsibility and risk-sharing mechanism of legitimate defense and the special attention of the law to the right of personality.
\end{abstract}

\section{Introduction}

February 17, 2017, Liaocheng City of Shandong Province Intermediate People's Court of first instance to intentional assault sentenced to imprisonment, the case of the results of the media after the disclosure, quickly lead to hot. The first instance verdict reads: In July 2014, located in Shandong Province Guanxian Industrial Park, Shandong Yuan Da Industry and Trade Co., Ltd. responsible person Su Yinxia to Zhao Rongrong loan 1 million yuan, orally 10\% monthly interest rate. April 14, 1616 pm 16 o'clock in the afternoon, Zhao Rongrong on the grounds of debt collection Guo Yan Gang and so on more than 10 people to Shandong Yuan Da Industry and Trade Co., Ltd. urged to the arrears in the factory reception room limit Su Yinxia and Su Yinxia son in the joy of personal freedom, And insulting words and deeds. 22:10 that night, the police arrived at the reception room after the police, asked the situation to the hospital to further understand the situation, the defendant in the joy of leaving the reception room was blocked, and Du Zhihao and others clashed, the defendant in the holding knife will Du Zhihao and so on 4 people stabbed, Du Zhihao due to hemorrhagic shock at 2 o'clock the next day to death, Yan Jianjun, Guo Yan Gang injury seriously injured two, Cheng Xuehe injury constitutes a minor injury two.

The court of first instance held that the defendant was unable to correctly handle the conflict, and that the guards were accused of intentional assault. The defendant in the Yu Huan guilty of intentional injury serious consequences, should bear the consequences of the crime with its considerable legal responsibility, in view of the victim of the case with the fault, and the defendant in the case of pleading to truthfully confess their own crimes, may be punished. Accordingly, the defendant in $\mathrm{Yu}$ Huan guilty intentional assault, sentenced to life imprisonment, deprivation of political rights for life.

Carefully read the verdict, the case caused so much social concern, mainly because the victim Du Zhihao and others in the process of illegal detention to take the challenge of the bottom line of human insult, and the police did not take any measures to stop unlawful infringement. The court of first 
instance standing behind the rational point of view, failed to fully consider the special situation in which the parties, and ultimately for the parties out of an ordinary person is difficult to complete the legal obligations, the judge once again torn social feelings, The fact that there is a clear flaw in the application of the legal norms, the fact that the first instance verdict is determined, it should be concluded that the crime is not guilty, this article Combined with the legitimate defense theory and legal provisions, the hot case of the ruling to explore, and strive to benefit the second instance verdict.

\section{The Misreading of the Justifiable Defense System in the First Instance}

\section{The judgment of the first instance ruled out the facts and reasons for the defense of the case}

The first instance verdict is not adopted by the defender regarding the defense of the proper defense of the guards, defending the defense, and reducing the penalty. It is considered that the real risk of violation of the right to life and health of Yu Huan and his mother is less, and there is no urgency of defense. Therefore, there is no unlawful infringement in the possession of the knife.

The first instance found that the case does not constitute a legitimate defense of the reasons include: 1 , there is no urgency of defense, Yu Huan and his mother's life and health rights are less likely to be violated; 2, do not have legitimate defense of the prerequisite for unlawful infringement, There is no prerequisite for defense, as long as it does not endanger human life and health, there is no prerequisite for defense, in other words, just defense can only defend the right to life and the right to health, the case suffered violations of personal liberty And the right of personality should not belong to the scope of defense. 3, the victim side of no one use the tools, so at least the use of tools to prevent the defense is not established.

From the reasons set forth in the judgment of the first instance, in particular, the prerequisites for the urgency and unlawful infringement of proper defense, and the expression of objective veto in the judgment, it can be inferred that the first instance judge has fully considered the criminal legal system and theory, On the full grasp of the criminal legal theory, however, these seemingly justified itself is full of misunderstanding of the legitimate defense system, whether it is a prerequisite for the defense of the conditions of understanding, or the awareness of the urgency of defense is undoubtedly biased And narrow, reflecting the court of first instance on the right to defend the right to fear and hesitate the traditional thinking set.

\section{Prerequisites for legitimate defence}

The first instance verdict completely negate the legitimate defense, stressed that the defendant in this case and his mother's right to life and health rights are less likely to be violated, that there is no legitimate defense of the premise of unlawful infringement, that is, natural exclusion of freedom Rights and personality rights infringement as a range of defense against unlawful infringement, this view does not meet the provisions of the Criminal Code, and therefore is not appropriate.

\section{Urgency Judgment of justifiable defense}

Urgency is one of the conditions of legitimate defense, urgency, although literally and critical, dangerous moment and so on, but in fact only to determine the time can be legitimate defense standards, this time limit is limited to the state of unlawful infringement, Therefore, the urgency of defending the defense first is to define the time of legitimate defense, that is, unlawful infringement has begun, and did not end, as long as meet this condition should be regarded as in line with the urgency of legitimate defense.

\section{The justification of legitimate defense}

\section{The results of the case should be common sense common sense to test.}

When the outcome of the case, do not meet the common sense of common sense, should be based on the law of the case is correct, the application of the law is accurate, whether to determine the facts are complete, the judiciary's emotions and thinking are disturbed and so on. Justice is the soul of justice, 
and fair and must be dealt with by the case to deal with, the judge of the law and the facts of the judgment process to meet the basic human relations, human nature and rational call. However, this is not just to break the bottom line of the law, contrary to the principle of legality, a modest focus on social effects is the responsibility of justice.

\section{Personality rights are an important right of citizens who should be protected}

Personality right is a basic right of citizens of modern society. People as an individual living in the group have their own psychological needs which are respected by others, recognized by society and recognized, the human body, senses and so on. So that, as a part of the modern civilization system, the legal system of each country is to protect the personality of citizens, our country is no exception, our country established the legal system of citizens' personality rights.

\section{The proof of the appropriateness of defense}

No doubt Yu Huan's behavior is legitimate defense, but whether it constitutes a defensive too this defense overdue? This article argues that the legitimate defensive acts in Hong Kong constitute a legitimate defense, and the comprehensive situation of the situation, although the guards of the anti-defensive behavior, although the more serious consequences, but the consequences are to stop the illegal infringement needs, and no choice.

\section{The strength of the defense must be achieved to stop the purpose of unlawful infringement}

The purpose of the defense system is to prevent the unlawful infringement through the defense, the protection of legitimate rights and interests, then take the means and strength of defense must first play a defensive role, can play to stop the purpose of unlawful infringement, otherwise the defense will lose its meaning.

\section{The strength of the defense is only necessary to adapt to the intensity of the infringement}

Legitimate defense can not exceed the necessary limits, which is the criminal law and criminal law theory of consensus, legitimate defense as a specific situation of relief, can not damage the great legal order to protect the smaller legal interests. In the legal protection of criminal law, human life rights are regarded as the highest right, in the case of possible damage to human life rights, defenders should be cautious obligations, and bear the resulting risks. On the question of how to judge the necessary limits, the criminal law theory mainly adopts the comprehensive judgment method which basically adapts, mainly through the unlawful infringement of the rights and interests of the criminal law, the nature of the criminal law, the means of unlawful infringement, the means of unlawful infringement, Behavior and defense behavior in which the objective background conditions and other aspects to grasp whether the basic adaptation.

\section{To determine whether the strength of defense should be appropriate to stand in the party's position}

China's judicial practice in the legitimate defense that there is a harsh momentum, in particular, serious consequences of casualties are generally identified as defensive too. But it is difficult for the public to agree that an innocent person in the face of illegal violations of the situation, choose to be able to implement their own defensive behavior, then immediately become guilty. "The practice department has consistently adhered to the post-judge path, and overly inclined to the objective results of the elements as a means of determining whether the defense exceeds the necessary limits, that is, to determine whether the defense to meet the limits of the requirements, usually by the judge based on the referee position The evidence of the fact that the object to be identified. "This way of judgment on the surface is both objective and realistic reality, but the lack of expectations of the possibility of legitimate defense is given by the individual to the individual in the emergency situation to take self-remedial means, Therefore, legitimate defense is neither a professional requirement, nor is it a manifestation of responsibility, then, for the proper defense of the right to judge the criteria 
should not be taken after the rational judgment criteria, but should stand in the party's point of view, at the time Under the circumstances, according to the judge at the time of the judge to determine the conclusion.

\section{Conclusion}

Since the establishment of a proper defense system in the law, it is necessary to allow citizens to exercise proper defense rights. In the course of exercising proper defense rights, if there is no better way to design a better but less damaging defense mode, What is the reason we have to let the guards bear the consequences of criminal responsibility? Unless the law requires the face of unlawful infringement, can only stand can not resist, obviously this is contrary to the provisions of the law, nor the basic logic of human nature and behavior. Legitimate defense system has been fully taken into account the human nature in the emergency situation will often be more fragile, and therefore, in the defense limits also set aside the corresponding fault-tolerant space.

In fact, whether it is standing in the perspective of Yu Huan or rational point of view of the spectator, if that Du Zhihao and others violations are illegal and already have a very serious degree, then it should be allowed to be infringed in Yu Huan people can defend, but What kind of means can he choose to defend? It is no possibility that wrestling has no possibility, when the threat and no effect, but to stimulate the approaching approaching, dangerous upgrade, in the joy of further defense against the people who carried out the damage, And ultimately prevented the perpetuation of illegal infringement. In view of this, in the defense of the defense is in line with the law, but also the choice of the scene had to, from the rationality to the defense strength of the master is actually appropriate. As for the emergence of Du Zhihao death this seemingly serious consequences, but the law did not follow the requirements of defender to grasp the accuracy. Therefore, Yu Huan's behavior in line with legitimate defense, and defensive behavior did not significantly exceed the necessary limits, and therefore is not guilty.

There are obvious problems in the judgment of the first instance, whether it is from the application of legal norms, legal norms or common sense, there are obvious problems, there is a big doubt, the case of the in-depth study and correct judgments, help to really establish a legitimate defense The rational use of the system, the expression of the law on the protection of personality rights concerns, as well as respect for human vulnerability, in this sense, no doubt the case has a sample effect.

\section{References}

[1] Ma Kechang. The General Theory of Crime Wuhan University Press, 1999, pp. 712.

[2] Hans Heinrich Jesseke, Thomas Wegent: German Criminal Law Textbook, translated by Xu Jiusheng, China Legal Press, 2001, pp. 587-588.

[3] (Japanese)Otsuka Ken: Introduction to Criminal Law (General) (Third Edition), translated by Feng Jun, Renmin University of China Press, 2003, pp. 273.

[4] Chen Zhonglin: Essays for Criminal Law, Law Press, 2003, pp. 38.

[5] Chen Zhonglin: Essays for Criminal Law, Law Press, 2003, pp. 39.

[6] Cheng Xiaoxue: Judicial decisions should be appropriate focus on social effects, Contained in Rule of law and society, 2016, Vol.16.

[7] Chen Xuan: Justification and Proportionality Principle - An attempt to explain the constitutionality of criminal law, Global Law Review, No. 6, 2016, pp. 41 (36-58).

[8] (German) Liszt: German Criminal Law Textbook (revised version), revised by (German) Schmidt, translated by Xu Jiusheng, revised by He Bingsong, Law Press, 2006, pp. 411. 
[9] Guo Zeqiang: New Horizon of Justifiable Defense Studies, China Social Science Press, 2010, pp. 109-112.

[10]Zhang Bao: Judicial Determination of the dilemma and the way out of defense, contained in the "Journal of Law", 2016, No. 10, pp. 97 (95 101).

[11]Guo Zeqiang: New Horizon of Just Defense Research, China Social Science Press, 2010, pp. 119.

[12] You Xiaohua: Criteria for Judging the Defendance of Defendance, Hebei Law, 2009, No. 4, pp. 161 (161 164).

[13](German) Liszt: German Criminal Law Textbook (revised version), revised by (German) Schmidt, translated by Xu Jiusheng, revised by He Bingsong, Law Press, 2006, pp. 411.

[14]Chen Xuan: Advocacy of the principle of risk sharing in legitimate defense, vol.1, pp. 106 (102-110).

[15]Feng Jun: Criminal Responsibility, Law Press, 1996, pp. 245. 